\title{
Comparison of investigation methods of heat injury in grapevine (Vitis) and assessment to heat tolerance in different cultivars and species
}

\author{
Hongguo Xu ${ }^{1,2}$, Guojie Liu', Guotian Liư ${ }^{2,3}$, Bofang Yan ${ }^{2,3}$, Wei Duan ${ }^{2}$, Lijun Wang ${ }^{2 *}$ and Shaohua Li $i^{2,4^{*}}$
}

\begin{abstract}
Background: In the context of global climate change, heat stress is becoming an increasingly important constraint on grapevine growth and berry quality. There is a need to breed new grape cultivars with heat tolerance and to design effective physiological defenses against heat stress. The investigation of heat injury to plants or tissues under high temperature is an important step in achieving these goals. At present, evaluation methods for heat injury include the gas exchange parameters of photosynthesis, membrane thermostability, chlorophyll content etc.; however, these methods have obvious disadvantages, such as insensitivity, inconvenience and delayed information. An effective and convenient method for investigating the heat injury of grapevine must be developed.

Results: In this study, an investigation protocol for a critical temperature $\left(47^{\circ} \mathrm{C}\right)$ and heat treatment time $(40 \mathrm{~min})$ was developed in detached grape leaves. Based on the results, we found that the OJIP test was superior to measuring electrolyte leakage or photosynthetic $\mathrm{O}_{2}$ evolution for investigating the heat injury of three cultivars of grapevine. Heat tolerance of 47 grape species and cultivars was evaluated through investigating heat injury using the OJIP test. Moreover, the electron transport chain (donor side, acceptor side and reaction center) of PSII in photosynthesis was further investigated.
\end{abstract}

Conclusions: The OJIP test was a rapid, sensitive and convenient method for investigating heat injury in grapevine. An analysis of PSII function using this method indicated that the acceptor side was less sensitive to heat than was the donor side or the reaction center in grape leaves. Among the 47 taxa evaluated (cultivars, hybrids, and wild species), heat tolerance varied largely in each genotype group: most wild species and hybrids between $V$. labrusca and $V$. vinifera had relatively strong heat tolerance, but most cultivars from $V$. vinifera had relatively weak heat tolerance.

\section{Background}

Grapevine is the most economically important fruit crop in the world, with its berries both eaten fresh and used for making wine, jam, juice, jelly, raisins and vinegar. Viticultural production is famously sensitive to climate [1-3], and temperature and moisture regimes are among the primary elements of grape terroir $[3,4]$. In many production regions, the maximum midday air temperature

\footnotetext{
*Correspondence: ljwang@ibcas.ac.cn; shhli@ibcas.ac.cn

${ }^{2}$ Key Laboratory of Plant Resources and Beijing Key Laboratory of Grape Science and Enology, Institute of Botany, the Chinese Academy of Sciences, Beijing 100093, People's Republic of China

${ }^{4}$ Key Laboratory of Plant Germplasm Enhancement and Specialty Agriculture, Wuhan Botanical Garden, the Chinese Academy of Sciences, Wuhan 430074, People's Republic of China

Full list of author information is available at the end of the article
}

may exceed $40^{\circ} \mathrm{C}$, with some regions exceeding $45^{\circ} \mathrm{C}$ [5-7]. High temperatures influence the development of plants and inhibit leaf photosynthesis. Exposure to high temperatures during flowering significantly inhibits berry set [8]. After fruit set, high temperatures are generally not favourable to the development secondary metabolites such as phenolic compounds [9,10] and aromatic volatiles [7]. High temperatures stimulate sugar accumulation [8], resulting in the production of wines with higher alcohol concentrations. To cope with heat stress, it is necessary to breed new cultivars with strong heat tolerance and to design effective physiological defenses against heat stress. Consequently, developing an effective and convenient method for evaluating the heat stress is a key goal. 
At high temperatures, cell injury and even death may occur, which may be attributed to a catastrophic collapse of cellular organization [11]. Several physiological traits have been investigated as indicators of heat injury: gas exchange parameters of photosynthesis, including net photosynthesis rate, photosynthetic $\mathrm{O}_{2}$ evolution rates and stomatal conductance [12-17]; membrane thermostability, including electrolyte leakage and the content of thiobarbituric acid-reactive-substances (TBARS) [18-20]; chlorophyll content [21-23]. However, these methods all have disadvantages, including insensitivity, inconvenience in field studies and the delay of information between the initial damage and the measurable effect(s). At present, a rapid, sensitive and convenient method of investigating heat injury for evaluating heat tolerance in grapevine must be developed.

The cell membrane is thought to be a site of primary physiological injury by heat stress [24]. The injury inflicted on leaf tissues under high stress weakens the cell membrane, which leads to a leakage of electrolyte out of the cell. Thus, measuring electrolyte leakage is a common evaluation method for heat injury. Photosynthesis, which is the basis of yield and quality and has long been recognized as one of the most heat-sensitive processes in plants [11], depends on the thylakoid membrane. However, it is difficult to evaluate the heat injury for a large number of plants by measuring the net photosynthesis rate with a photosynthesis system (such as the Li-6400) or the photosynthetic $\mathrm{O}_{2}$ evolution rates with an oxygen electrode system due to the time required per plant. Three major heat-sensitive sites occur in the photosynthetic apparatus or process: the photosystems, mainly photosystem II (PSII), and the ATP-generating and carbon assimilation processes $[25,26]$. Inactivation of PSII by heat stress is related to damage of the donor side, the reaction center and the acceptor side of the photosystem's electronic transport chain [27]. The inhibition of PSII leads to a change in variable chlorophyll $a$ fluorescence, and in vivo chlorophyll may be used to detect changes in the photosynthetic apparatus [28,29]. Strasser et al. [30] developed a method (chlorophyll $a$ fluorescence transient) for the analysis of the kinetics of fast fluorescence increases, using nondestructive measurements that can be taken with a high resolution of $10 \mu \mathrm{s}$. All oxygenic photosynthetic materials investigated to date have shown a polyphasic increase in fluorescence consisting of a sequence of phases, denoted as $\mathrm{O}, \mathrm{J}, \mathrm{I}$ and $\mathrm{P}$. Therefore, the measurement of this chlorophyll $a$ fluorescence transient is also called the OJIP test. The OJIP test has become a powerful tool for the in vivo investigation of PSII functioning, including its energy absorption, trapping and electron transport [28,30-33]. In crops such as wheat, cabbage and raspberry, the OJIP test has been applied in the investigation of heat injury [34-36]. However, no complete comparison study has yet been conducted between the OJIP test and traditional methods such as the measurement of electrolyte leakage and photosynthetic $\mathrm{O}_{2}$ evolution rates, and no information exists on the use of OJIP parameters for identifying heat tolerance in grapevine germplasm.

The aims of this study were as follow: (1) to establish a heat stress protocol for grapevine; (2) to determine which method among the OJIP test, the measurement of photosynthetic $\mathrm{O}_{2}$ evolution rates and electrolyte leakage was superior for assessing the heat injury of grapevines; and (3) to evaluate the heat tolerance of 47 grapevine species or cultivars through determining heat injury by the best method.

\section{Results}

The critical temperature $\left(T_{c}\right)$ for the investigation of heat injury of grapevines

For investigating the heat injury of grapevines, a critical temperature $\left(T_{c}\right)$ was first established. According to Weng and Lai [37], $\mathrm{T}_{\mathrm{c}}$ may be determined from the intersection of the two regression lines extrapolated from the slowand fast-rising portions of the temperature-dependent $F_{o}$ and $F_{v} / F_{m}$ responses obtained from the OJIP test (see Method section). As shown in Figure $1, F_{o}$ and $F_{v} / F_{m}$ responded differently to a gradual increase of temperature in the leaves of 'Jingxiu', 'Riesling' and spine grape. These values remained relatively stable below a critical temperature, then started to increase $\left(\mathrm{F}_{\mathrm{o}}\right)$ or decrease $\left(F_{v} / F_{m}\right)$ sharply. Little difference was observed in the critical values of 'Jingxiu', 'Riesling' and spine grape: all were approximately $47^{\circ} \mathrm{C}$ based on the $\mathrm{F}_{\mathrm{v}} / \mathrm{F}_{\mathrm{m}}$ (from $46.5^{\circ} \mathrm{C}$ to $47.8^{\circ} \mathrm{C}$ ) and $\mathrm{F}_{\mathrm{o}}$ (from $46.5^{\circ} \mathrm{C}$ to $47.1^{\circ} \mathrm{C}$ ) values. Therefore, $47^{\circ} \mathrm{C}$ was selected as the $\mathrm{T}_{\mathrm{c}}$ for evaluating the heat injury of grapevines.

\section{The comparison of investigation methods for heat injury of grapevines under $T_{c}$}

The electrolyte leakage, photosynthetic $\mathrm{O}_{2}$ evolution rate and OJIP test have all been used to evaluate the heat tolerance of plants $[19,20,26,38,39]$. We further compared the characteristics of the above methods using the responses of leaf discs from 'Jinxiu', 'Riesling' and spine grape to heat stress at $T_{c}$ over $50 \mathrm{~min}$. In the OJIP test, we chose parameter $F_{v} / F_{m}$ to investigate heat injury. In the photosynthetic $\mathrm{O}_{2}$ evolution rate and electrolyte leakage methods, the $\mathrm{O}_{2}$ evolution rate and relative injury index (RII) (indicating the degree of injury to the cell membrane) were used as investigation parameters, respectively. Following heat stress at $T_{c}$, the $F_{v} / F_{m}$ and $\mathrm{O}_{2}$ evolution rate values of the three grapevines gradually declined, while their RII values increased (Figure 2). However, the sensitivity to heat stress varied among the three cultivars. Significant differences in $F_{v} / F_{m}$ 


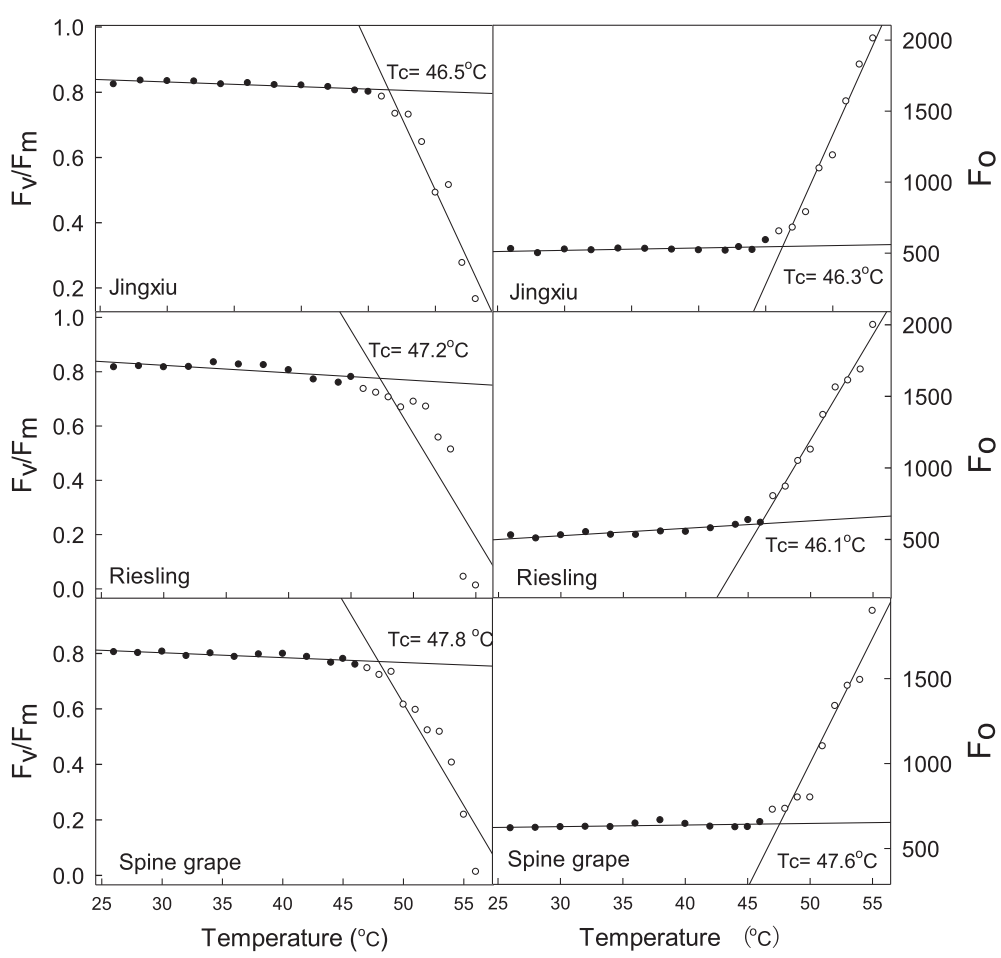

Figure 1 Establishing the critical temperature $\left(T_{c}\right)$ for investigating the heat injury of grape leaves using the chlorophyll $a$ fluorescence parameters $F_{v} / F_{m}$ and $F_{o} . T_{c}$ was determined from the intersection of the two regression lines extrapolated from the slow- and fast-rising portions of the temperature-dependent $F_{v} / F_{m}$ and $F_{o}$ response.

were observed among the three cultivars until after 20 min of heat stress, and significant differences in $\mathrm{O}_{2}$ evolution rates and RII were seen until after $30 \mathrm{~min}$ of stress. Significantly lower $\mathrm{F}_{\mathrm{v}} / \mathrm{F}_{\mathrm{m}}$ and $\mathrm{O}_{2}$ evolution rates, as well as a higher RII, were observed in 'Jinxiu' than in spine grape. The values of the three parameters in 'Riesling' fell between those of 'Jinxiu' and spine grape. At $40 \mathrm{~min}$ after the application of heat stress, the three cultivars differed significantly for $\mathrm{F}_{\mathrm{v}} / \mathrm{F}_{\mathrm{m}}, \mathrm{O}_{2}$ evolution rate and RII. Moreover, at this point, the difference among the three cultivars for $\mathrm{F}_{\mathrm{v}} / \mathrm{F}_{\mathrm{m}}$ was significantly larger than for $\mathrm{O}_{2}$ evolution rate or RII. At the end of the experiment, i.e., $50 \mathrm{~min}$ after the leaf discs were subjected to heat stress, there was a significant difference only in $\mathrm{F}_{\mathrm{v}} / \mathrm{F}_{\mathrm{m}}$ among the three cultivars. For both $\mathrm{O}_{2}$ evolution rate and RII, the significant differences disappeared between 'Jingxiu' and 'Riesling'. In general, the heat injury of spine grape was the least, followed by the tolerances of 'Riesling' and 'Jinxiu' (Figure 2). The data indicated that $40 \mathrm{~min}$ is an appropriate duration of heat stress at $\mathrm{T}_{\mathrm{c}}\left(47^{\circ} \mathrm{C}\right)$ for investigating the heat injury of grapevines and that the OJIP test was the most suitable among the three methods due to the sensitivity of its parameters.
Electron transport chain of PSII in grapevines under $T_{c}$ The OJIP test may also reveal information regarding the electron transport chain of PSII [32]. The response of the electron transport chain of PSII to heat stress under $\mathrm{T}_{\mathrm{c}}\left(47^{\circ} \mathrm{C}\right)$ was investigated using the OJIP test in 'Jingxiu', 'Riesling' and spine grape. The value of $\mathrm{W}_{\mathrm{k}}$ expresses the changes of the amplitude in the K step in the OJIP test, which is used as a specific indicator of damage to the PSII donor side. In general, the $\mathrm{W}_{\mathrm{k}}$ values of the three cultivars increased sharply by $10 \mathrm{~min}$ after the initiation of heat stress, then increased more slowly in 'Jingxiu' and 'Riesling' from 10 to $50 \mathrm{~min}$ over the experiment (Figure 3A). However, the $W_{k}$ of spine grape changed little after $10 \mathrm{~min}$ and was significantly lower than that of the other two cultivars throughout the heat stress period. $\mathrm{RC}_{\mathrm{QA}}$ indicates the density of the PSII reaction centers $[40,41]$. The $\mathrm{RC}_{\mathrm{QA}}$ in all genotypes declined rapidly within $10 \mathrm{~min}$ of heat stress and continued to decrease slowly over the experiment at $\mathrm{T}_{\mathrm{c}}$. The density of $\mathrm{RC}_{\mathrm{QA}}$ in spine grape was significantly higher than in the other two cultivars after $10 \mathrm{~min}$ (Figure 3B). The changes in the quantum yield of electron transport $\left(\phi_{\mathrm{Eo}}\right)$ in the grape leaves during heat stress are shown in Figure 3C. $\phi_{\text {Eo }}$ was used as an indicator of the acceptor side of the electron transport chain of 


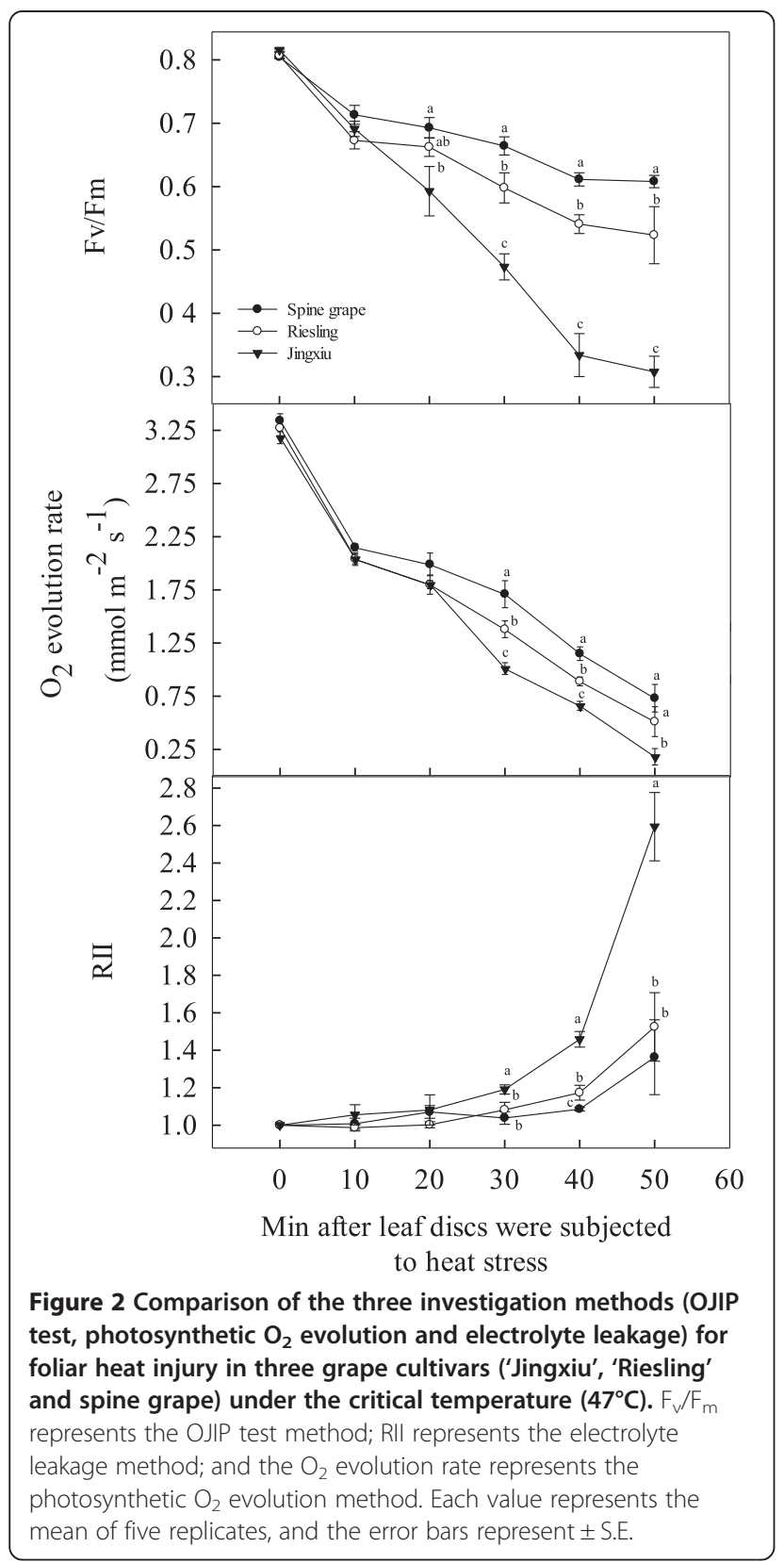

PSII $[40,41]$. Heat stress at $47^{\circ} \mathrm{C}$ altered the $\phi_{\text {Eo }}$ values in the grape leaves of all three cultivars. These values were stable after $10 \mathrm{~min}$ of heat stress but rapidly decreased thereafter. The spine grape and 'Riesling' had higher $\phi_{\text {Eo }}$ values than did 'Jingxiu'.

\section{Evaluation of heat tolerance in $\mathbf{4 7}$ cultivars (or species) of grapevine under $\mathrm{T}_{\mathrm{c}}$}

Generally, heat injury under heat temperature may indirectly reflect heat tolerance in plants. The more serious heat injury, the weaker heat tolerance. In this study, for evaluating heat tolerance of 47 grape cultivars (or species), the parameter $F_{v} / F_{m}$ of the OJIP test was chosen to

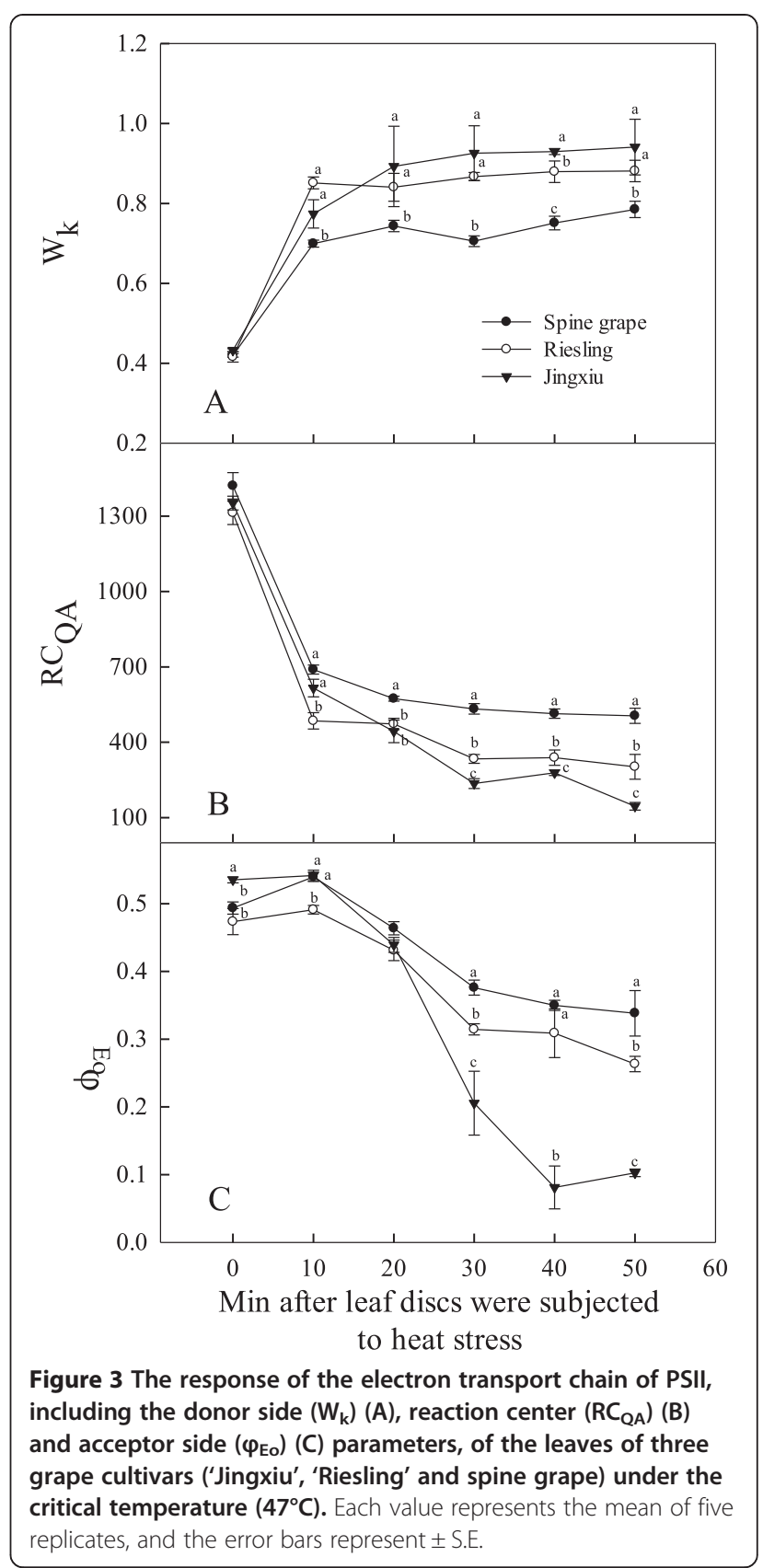

investigate their heat injury under $\mathrm{T}_{\mathrm{c}}$. We measured the $\mathrm{F}_{\mathrm{v}} / \mathrm{F}_{\mathrm{m}}$ of these genotypes in May, June and July of 2012 and June and July of 2013. Positive correlations for the $\mathrm{F}_{\mathrm{v}} / \mathrm{F}_{\mathrm{m}}$ values in these grape leaves were observed among the different sampling times (Table 1). Our experiment was conducted in Beijing (latitude from $39^{\circ} 26^{\prime}$ to $41^{\circ} 03^{\prime}$, longitude from $115^{\circ} 25^{\prime}$ to $117^{\circ} 30^{\prime}$ ), where the average daily temperature $\left(16^{\circ} \mathrm{C}-25^{\circ} \mathrm{C}\right)$ and lower rainfall in May are more suitable for grapevine growth than are conditions in June and July. Therefore, only the data from May 2012 are reported in this paper, as shown in Table 2 . The $\mathrm{F}_{\mathrm{v}} / \mathrm{F}_{\mathrm{m}}$ values varied greatly with the genetic 
Table 1 Correlation analysis of the chlorophyll $a$ fluorescence parameter $F_{v} / F_{m}$ among different sampling times in grape leaves under a heat stress of $47^{\circ} \mathrm{C}$ for $\mathbf{4 0} \mathrm{min}$

\begin{tabular}{|c|c|c|c|c|c|}
\hline & $F_{v} / F_{m}(05 / 2012)$ & $F_{v} / F_{m}(06 / 2012)$ & $F_{v} / F_{m}(07 / 2012)$ & $F_{v} / F_{m}(06 / 2013)$ & $F_{v} / F_{m}(07 / 2013)$ \\
\hline$F_{v} / F_{m}(05 / 2012)$ & 1 & $0.834^{* *}$ & $0.623^{* *}$ & $0.542^{* *}$ & $0.602^{* *}$ \\
\hline $\mathrm{F}_{\mathrm{v}} / \mathrm{F}_{\mathrm{m}}(06 / 2012)$ & & 1 & $0.695^{* *}$ & $0.683^{* *}$ & $0.580^{* *}$ \\
\hline $\mathrm{F}_{\mathrm{v}} / \mathrm{F}_{\mathrm{m}}(07 / 2012)$ & & & 1 & $0.640^{* *}$ & $0.411^{* *}$ \\
\hline$F_{v} / F_{m}(06 / 2013)$ & & & & 1 & $0.480^{* *}$ \\
\hline $\mathrm{F}_{\mathrm{v}} / \mathrm{F}_{\mathrm{m}}(07 / 2013)$ & & & & & 1 \\
\hline
\end{tabular}

The asterisks * and ${ }^{*}$ indicate a significant correlation at $P<0.05$ and $P<0.01$, respectively.

backgrounds in each genotype group, especially in $V$. vinifera. Most wild grapevines had higher $\mathrm{F}_{\mathrm{v}} / \mathrm{F}_{\mathrm{m}}$ values than did domesticated cultivars. The highest $\mathrm{F}_{\mathrm{v}} / \mathrm{F}_{\mathrm{m}}$ value was found in $V$. davidii (1, number in the Table 2, same below) at 0.68 , followed by a value of 0.62 in $V$. ripara (10). V. rubra (9) had the lowest $\mathrm{F}_{\mathrm{v}} / \mathrm{F}_{\mathrm{m}}$ value at only 0.39 . Interspecific hybrids among wild grapevines had moderate $F_{v} / F_{m}$ values, ranging from 0.54 to 0.32 with an average value of 0.43 . However, interspecific hybrids between $V$. vinifera and $V$. labrusca had relatively high $F_{v} / F_{m}$ values. The highest $F_{v} / F_{m}$ values were found in 'Kangtai' (18) at 0.68, followed by 'Mitsushiru' (19) at 0.65. 'Jingyou' (26) had the lowest $\mathrm{F}_{\mathrm{v}} / \mathrm{F}_{\mathrm{m}}$ value at 0.34 . The $\mathrm{F}_{\mathrm{v}} / \mathrm{F}_{\mathrm{m}}$ values of the cultivars of $V$. vinifera ranged from 0.68 to 0.34 , and most cultivars had lower $F_{v} / F_{m}$ values. The highest $F_{v} / F_{m}$ values were found in 'Riesling' (28) and 'Cabernet Sauvignon' (29) at 0.63 each, followed by 'Black Balad' at 0.61. 'Jingyu' (42), 'Muscat Hamburg' (45), 'Cabernet Franc' (43) and 'Yan73' (44) all had very low $\mathrm{F}_{\mathrm{v}} / \mathrm{F}_{\mathrm{m}}$ values of only $0.25,0.24,0.23$ and 0.20 , respectively.

To reveal the relationship between the electron transport chain of PSII and the heat tolrance of grape leaves, the $\mathrm{F}_{\mathrm{v}} / \mathrm{F}_{\mathrm{m}}, \mathrm{W}_{\mathrm{k}}, \mathrm{RC}_{\mathrm{QA}}$ and $\phi_{\mathrm{Eo}}$ of the 47 grape cultivars (or species) were further analyzed using correlation analysis based on the data from May 2012. Table 3 shows that $\mathrm{F}_{\mathrm{v}} / \mathrm{F}_{\mathrm{m}}$ was positively correlated with $\mathrm{RC}_{\mathrm{QA}}$ and $\phi_{\mathrm{Eo}}$ but negative correlated with $\mathrm{W}_{\mathrm{k}}$, indicating that higher $\mathrm{F}_{\mathrm{v}} / \mathrm{F}_{\mathrm{m}}$ values were associated with higher $\mathrm{RC}_{\mathrm{QA}}$ and $\phi_{\mathrm{Eo}}$ values but lower $W_{k}$ values. These results suggest that the heat tolerance of grapevine is associated with the electron transport chain, including the donor side, reaction center and acceptor side of PSII.

\section{Discussion}

\section{Methods of investigating heat injury in grapevines}

As determined by Weng and Lai [37], $\mathrm{T}_{\mathrm{c}}$ was easily calculated as $47^{\circ} \mathrm{C}$ using the OJIP test parameters of $F_{o}$ and $\mathrm{F}_{\mathrm{v}} / \mathrm{F}_{\mathrm{m}}$. Based on this result, the heat injury of 'Jingxiu', 'Reisling' and spine grape was investigated using three methods (OJIP test, photosynthetic $\mathrm{O}_{2}$ evolution rates and electrolyte leakage). These methods led to the same conclusion: the heat injury of spine grape was the least, followed by 'Riesling' and 'Jinxiu'. Although the three methods obtained the same results, they exhibited different characteristics. First, the processes of measuring electrolyte leakage and photosynthetic $\mathrm{O}_{2}$ evolution rates were more complex and required more time than the OJIP test (see Methods section for details). Second, the measurement of electrolyte leakage and photosynthetic $\mathrm{O}_{2}$ evolution rates must be conducted in the lab and requires small leaf discs. The former method requires a conductivity meter and a water bath, while the later requires an oxygen electrode system, a computer and a water bath. The OJIP test can be conducted in the lab or the field, and either leaf discs or whole leaves may be measured using the Handy Plant Efficiency Analyzer (volume: $175 \times 80 \times 40 \mathrm{~mm}^{3}$; Weight: $0.65 \mathrm{Kg}$ ). Third, measuring electrolyte leakage or photosynthetic $\mathrm{O}_{2}$ evolution rates yields only a single parameter, but the OJIP test can produce several parameters, including information regarding the electron transport chain of the photosynthetic apparatus. Fourth, the sensitivity of the three methods differed. As shown in Figure 2, significant differences in the $\mathrm{F}_{\mathrm{v}} / \mathrm{F}_{\mathrm{m}}$ and $\mathrm{O}_{2}$ evolution rate values among 'Jinxiu', 'Riesling' and spine grape appeared after $30 \mathrm{~min}$ of heat stress at $\mathrm{T}_{\mathrm{c}}$, but differences in the RII values appeared only after $40 \mathrm{~min}$. After $50 \mathrm{~min}$ of heat stress at $\mathrm{T}_{c}$, the differences in $\mathrm{O}_{2}$ evolution rate and RII values between 'Jinxiu' and 'Riesling' disappeared, but the differences of $F_{v} / F_{m}$ among the three cultivars remained. In general, the OJIP test was a rapid, sensitive and convenient method for measuring heat injury in grapevine. Moreover, the reproducibility of the method is very high, as shown in the correlation analysis between different years and different months (Table 1). Additionally, the Handy Plant Efficiency Analyzer may be used directly in the field. However, this evaluation relies primarily on photosynthesis and does not consider other physiological processes. The results of this study may be further applied in molecular breeding and quantitative trait analysis (QTL) by providing stable, sensitive phenotypic data for heat injury.

\section{Heat injury in grape leaves is related to the} photosynthetic electron transport chain of PSII

Photosynthesis, especially the electron transport chain of PSII, is highly sensitive to high-temperature stress $[42,43]$. 
Table 2 Heat tolerance of grape cultivars or species evaluated using the chlorophyll a fluorescence parameter $F_{v} / F_{m}$

\begin{tabular}{|c|c|c|c|c|}
\hline No & Cultivars or species & $\mathrm{F}_{\mathrm{v}} / \mathrm{F}_{\mathrm{m}}$ & Germplasm group & Average $F_{v} / F_{m}$ in a group \\
\hline 1 & V. davidii & $0.68 \pm 0.01 a$ & \multirow{10}{*}{ Wild grape } & \multirow{10}{*}{$0.51 \pm 0.03 a$} \\
\hline 2 & V. amurensis & $0.55 \pm 0.02 b c$ & & \\
\hline 3 & V. pseudoreticulata & $0.41 \pm 0.04 \mathrm{e}$ & & \\
\hline 4 & V. flexuosa & $0.40 \pm 0.02 \mathrm{e}$ & & \\
\hline 5 & V. bryoniaefolia & $0.52 \pm 0.04 \mathrm{~cd}$ & & \\
\hline 6 & Shuangqing (V. amurensis) & $0.58 \pm 0.01 b c$ & & \\
\hline 7 & V. cinerea & $0.55 \pm 0.02 b c$ & & \\
\hline 8 & V. aestivalis & $0.46 \pm 0.03 \mathrm{de}$ & & \\
\hline 9 & V. rubra & $0.39 \pm 0.03 e$ & & \\
\hline 10 & V. ripara & $0.62 \pm 0.01 \mathrm{ab}$ & & \\
\hline 11 & 5BB $(V$. berlandier $\times V$. ripara $)$ & $0.33 \pm 0.02 c$ & \multirow{7}{*}{ Hybrids among wild grape } & \multirow{7}{*}{$0.43 \pm 0.03 a b$} \\
\hline 12 & $5 C(V$. berlandier $\times V$. ripara $)$ & $0.53 \pm 0.04 a$ & & \\
\hline 13 & SO4 $(V$. berlandier $\times V$. ripara) & $0.50 \pm 0.03 \mathrm{ab}$ & & \\
\hline 14 & Beichun ( $V$. vinifera $\times V$. amurensis) & $0.41 \pm 0.03 b c$ & & \\
\hline 15 & Beihong $(V$. vinifera $\times V$. amurensis) & $0.32 \pm 0.02 c$ & & \\
\hline 16 & Beifeng $(V$. vinifera $\times V$. adstricta $)$ & $0.48 \pm 0.01 \mathrm{ab}$ & & \\
\hline 17 & Beta (V. labrusca $\times$ V. ripara) & $0.44 \pm 0.05 a b$ & & \\
\hline 18 & Kangtai & $0.68 \pm 0.01 a$ & \multirow{10}{*}{$\begin{array}{l}\text { Hybrids between } \\
\text { V. vinifera and V. labrusca }\end{array}$} & \multirow{10}{*}{$0.50 \pm 0.04 a$} \\
\hline 19 & Mitsushiru & $0.65 \pm 0.01 a$ & & \\
\hline 20 & Kyoho & $0.55 \pm 0.03 b$ & & \\
\hline 21 & Takasumi & $0.50 \pm 0.02 b c$ & & \\
\hline 22 & Gaoqi & $0.49 \pm 0.02 b c$ & & \\
\hline 23 & Izunishiki & $0.46 \pm 0.04 c$ & & \\
\hline 24 & Jingya & $0.44 \pm 0.03 c$ & & \\
\hline 25 & Fujiminori Grape & $0.35 \pm 0.04 d$ & & \\
\hline 26 & Jingyou & $0.34 \pm 0.02 d$ & & \\
\hline 27 & Parasaurolophus & $0.56 \pm 0.02 b$ & & \\
\hline 28 & Riesling & $0.63 \pm 0.02 a$ & & \\
\hline 29 & Cabernet Sauvignon & $0.63 \pm 0.01 a$ & & \\
\hline 30 & Black balad & $0.61 \pm 0.03 a$ & & \\
\hline 31 & Red balad & $0.51 \pm 0.02 b$ & & \\
\hline 32 & Chardonnay & $0.48 \pm 0.04 b c$ & & \\
\hline 33 & Ruby Seedless & $0.42 \pm 0.03 \mathrm{def}$ & & \\
\hline 34 & Alexander & $0.39 \pm 0.04$ cde & & \\
\hline 35 & Xiangfei & $0.37 \pm 0.02 \mathrm{def}$ & & \\
\hline 36 & Jingxiangyu & $0.36 \pm 0.03 \mathrm{def}$ & & \\
\hline 37 & Italian Riesling & $0.34 \pm 0.07$ efg & & \\
\hline 38 & Red Globe & $0.34 \pm 0.01 \mathrm{efg}$ & V. vinifera & $0.38 \pm 0.03 b$ \\
\hline 39 & Merlot & $0.33 \pm 0.01$ efg & & \\
\hline 40 & Cardinal & $0.28 \pm 0.02 \mathrm{fgh}$ & & \\
\hline 41 & Gros Colman & $0.28 \pm 0.03 g h$ & & \\
\hline 42 & Jingyu & $0.25 \pm 0.01 \mathrm{gh}$ & & \\
\hline 43 & Cabernet Franc & $0.23 \pm 0.02 \mathrm{~h}$ & & \\
\hline
\end{tabular}


Table 2 Heat tolerance of grape cultivars or species evaluated using the chlorophyll a fluorescence parameter $F_{v} / F_{m}$ (Continued)

\begin{tabular}{lll}
\hline 44 & Yan73 & $0.19 \pm 0.02 \mathrm{~h}$ \\
45 & Muscat & $0.24 \pm 0.02 \mathrm{~h}$ \\
46 & Nilawa & $0.25 \pm 0.01 \mathrm{gh}$ \\
47 & Jingyan & $0.45 \pm 0.02 \mathrm{bcd}$ \\
\hline
\end{tabular}

Values are means \pm S.E; Different letters indicate means are significantly different at $P<0.05$.

However, it is difficult to pinpoint the specific limiting steps that control the temperature response of the electron transport chain [44]. In our study, the decrease of the photosynthetic $\mathrm{O}_{2}$ evolution rate under heat stress was associated with electron transport capacity, which showed that the PSII of the photosynthetic apparatus was damaged. The different sensitivities of the parameters derived from the OJIP test may reflect the heterogeneous behavior of PSII under heat stress conditions. $\mathrm{W}_{\mathrm{k}}$ expresses the $\mathrm{K}$ step in the OJIP test, which is used as a specific indicator of damage to the PSII donor side related to the oxygen evolving complex (OEC) during heat stress. In this study, the $\mathrm{W}_{\mathrm{K}}$ value increased significantly by $10 \mathrm{~min}$ in all grape genotypes during the heat treatment, demonstrating that the OEC is one of the most vulnerable complexes of the photosynthetic electron transport chain. The results also showed that the stability of the OEC differs among genotypes, as the OECs of 'Jingxiu' and 'Riesling' were more vulnerable than those of the other genotypes.

The density of $\mathrm{RC}_{\mathrm{QA}}$ may reflect the density of $\mathrm{Q}_{\mathrm{A}}$-reducing PSII reaction centers [41], and the PSII reaction center is also one of the sites damaged by heat stress [45]. In our study, during heat stress at $47^{\circ} \mathrm{C}$, the density of $\mathrm{RC}_{\mathrm{QA}}$ decreased rapidly by $10 \mathrm{~min}$ for all genotypes, which indicated that the PSII reaction center was sensitive to heat and that the thermostability of the PSII reaction center differed among cultivars. The parameter $\phi_{\text {Eo }}$ represents the quantum yield or the energy distribution ratio of the acceptor side of PSII. The decrease in $\phi_{\text {Eo }}$ showed that the activity of electron transport beyond $\mathrm{Q}_{\mathrm{A}}$ was inhibited in grape leaves after $50 \mathrm{~min}$ of heat stress, but after only $10 \mathrm{~min}$, the $\phi_{\text {Eo }}$ values showed almost no change. These results indicated that while heat stress damaged the acceptor side of PSII, this structure was relatively stable in the initial stages of heat stress. The

Table 3 Correlation analysis among $\mathrm{F}_{\mathrm{v}} / \mathrm{F}_{\mathrm{m}}, \mathrm{W}_{\mathrm{k}}, \mathrm{RC}_{\mathrm{QA}}$ and $\varphi_{\text {Eo }}$

\begin{tabular}{lcccc}
\hline & $\mathbf{F}_{\mathbf{v}} / \mathbf{F}_{\mathbf{m}}$ & $\mathbf{R C}_{\mathbf{Q A}}$ & $\boldsymbol{\varphi}_{\text {Eo }}$ & $\mathbf{W}_{\mathbf{k}}$ \\
\hline $\mathrm{F}_{\mathbf{v}} / \mathrm{F}_{\mathrm{m}}$ & 1.00 & $0.84^{* *}$ & $0.79^{* *}$ & $-0.41^{* *}$ \\
\hline $\mathrm{RC}_{\mathrm{QA}}$ & 1.00 & $0.49^{* *}$ & $-0.73^{* *}$ \\
\hline$\varphi_{\text {EO }}$ & & 1.00 & -0.03 \\
\hline$W_{\mathrm{k}}$ & & & 1.00 \\
\hline
\end{tabular}

The asterisks * and ** indicate a significant correlation at $P<0.05$ and $P<0.01$, respectively. correlation analysis of the evaluation of different cultivars (species) further corroborated these results (Table 3). Therefore, the OJIP test can also reveal the relationship between heat injury in grape leaves and the photosynthetic electron transport chain of PSII.

\section{Conclusions}

The OJIP test was quicker, more sensitive and more convenient for investigating the heat injury of grape leaves than were measurements of photosynthetic $\mathrm{O}_{2}$ evolution rates or electrolyte leakage. Moreover, PSII functional analysis using the OJIP test indicated that the acceptor side of the photosystem II was less damaged by heat than were the donor side or the reaction center in grape leaves. The heat tolerance of 47 cultivars (or species) was evaluated by determining heat injury using this method. In general, the heat tolerance among cultivars or species varied largely in each genotype group. Most wild species and some hybrids of $V$. labrusca and $V$. vinifera had relatively strong heat tolerance, while most cultivars of $V$. vinifera had relatively weak heat tolerance.

\section{Methods}

\section{Plant materials}

A total of 47 wild species and cultivars were used in this study (Table 4). All of the grapevines were planted at the Germplasm Repository for Grapevines in the Institute of Botany of the Chinese Academy of Sciences, located in Beijing, in the spring of 1993. The vines, trained to bilateral cordons, were spaced $1.5 \mathrm{~m}$ apart within the row and $2.5 \mathrm{~m}$ apart between the rows with a northsouth row orientation. All vines were subjected to similar management practices for irrigation, fertilization, soil management, pruning, and disease control. Healthy leaves of approximately 30 days in age were used in this study. In May, June and July of 2012 and June and July of 2013, samples were taken in the morning, placed in the dark with the petiole in water, and then treated by heat stress.

\section{Heat stress process, critical temperature and appropriate} heat stress time

The heat stress process was as follows: leaf discs $(5.5 \mathrm{~cm}$ in diameter) were cut from the detached sample leaves, wrapped in a wet paper towel and placed in a small 
Table 4 Grape cultivars or species used in this study

\begin{tabular}{|c|c|c|}
\hline Germplasm groups & Cultivar number & Cultivars \\
\hline Wild grape & 10 & $\begin{array}{l}\text { V. davidii (1), V. amurensis (2), V. pseudoreticulata (3), V. flexuosa (4), V. bryoniaefolia (5), Shuangqing } \\
\text { (V. amurensis, 6), V. cinerea (7), V. aestivalis (8), V. rubra (9), V. ripara (10) }\end{array}$ \\
\hline Hybrids among wild grape & 7 & $\begin{array}{l}\text { 5BB }(V \text {. berlandier } \times V \text {. ripara) }(11), 5 C(V \text {. berlandier } \times V \text {. ripara) }(12) \text {, SO4 }(V \text {. berlandier } \times V \text {. ripara) (13), } \\
\text { Beichun }(V \text {. vinifera } \times V \text {. amurensis) (14), Beihong }(V \text {. vinifera } \times V \text {. amurensis) (15), Beifeng (V. vinifera } \times \\
V \text {. adstricta) (16), Beta (V. labrusca } \times V \text {. ripara) (17) }\end{array}$ \\
\hline \multirow{2}{*}{$\begin{array}{l}\text { Hybrids between } V \text {. vinifera } \\
\text { and } V \text {. labrusca }\end{array}$} & \multirow[t]{2}{*}{10} & Kangtai (18), Mitsushiru (19), Kyoho (20), Takasumi \\
\hline & & (21), Gaoqi (22), Izunishiki (23), Jingya (24), Fujiminori Grape (25), Jingyou (26), Parasaurolophus (27) \\
\hline V. vinifera & 20 & $\begin{array}{l}\text { Riesling (28), Cabernet Sauvignon (29), Black balad (30), Red balad (31), Chardonnay (32), Ruby } \\
\text { Seedless (33), Alexander (34), Xiangfei (35), Jingxiangyu (36), Red Globe (37), Italian Riesling (38), } \\
\text { Merlot (39), Cardinal (40), Gros Colman (41), Jingyu (42), Cabernet Franc (43), Yan73 (44), Muscat } \\
\text { Hamburg (45), Nilawa (46), Jingyan (47) }\end{array}$ \\
\hline
\end{tabular}

vessel made of aluminum foil. The vessels were then floated on water in a temperature-controlled water bath. To compare the effects of different evaluation methods for heat injury and to evaluate heat tolerance in the different species and cultivars, the critical temperature $\left(\mathrm{T}_{\mathrm{c}}\right)$ and appropriate heat stress time were first determined. According to the methods of Weng and Lai [37], $\mathrm{T}_{\mathrm{c}}$ is the temperature at which the chlorophyll $a$ fluorescence parameter $F_{o}$ starts to increase sharply or $\mathrm{F}_{\mathrm{v}} / \mathrm{F}_{\mathrm{m}}$ decreases sharply. The experiment was conducted in three cultivars or species: 'Jingxiu' ( $V$. vinifera), 'Riesling' ( $V$. vinifera) and spine grape ( $V$. davidii) in May of 2012. Leaf discs of each cultivar were heated from $25^{\circ} \mathrm{C}$ to $55^{\circ} \mathrm{C}$ at a rate of approximately $1^{\circ} \mathrm{C} \mathrm{min}^{-1}$ in darkness, according to the above heat stress process. $F_{v} / F_{m}$ and $F_{o}$ were measured every 1-2 min using a Handy Plant Efficiency Analyzer (Hansatech Instruments, King's Lynn, Norfolk, UK) (details shown below). $\mathrm{T}_{\mathrm{c}}$ was determined from the intersection of the two regression lines extrapolated from the slow- and fast-rising portions of the temperaturedependent fluorescence parameter $F_{o}$ or $F_{v} / F_{m}$ responses. To determine the appropriate heat stress duration, the leaf discs were exposed to $T_{c}$ for $50 \mathrm{~min}$, and the $F_{v} / F_{m}$, electrolyte leakage and photosynthetic $\mathrm{O}_{2}$ evolution rates were determined every $10 \mathrm{~min}$. The time at which a significant difference for each parameter was observed among the three cultivars was regarded as the appropriate heat stress time for the study.

\section{Three methods of investigating heat injury (electrolyte leakage, photosynthetic $\mathrm{O}_{2}$ evolution rate, chlorophyll $a$ fluorescence)}

After determining the critical temperature and appropriate heat stress time, the three investigating methods, electrolyte leakage, photosynthetic $\mathrm{O}_{2}$ evolution rate and the OJIP test, were compared in May of 2012.

To measure electrolyte leakage, the heat-stressed leaf discs $(5.5 \mathrm{~cm}$ in diameter) were again cut into smaller leaf discs (1 cm in diameter) and washed with deionized water, then incubated in $10 \mathrm{ml}$ of deionized water at $25^{\circ} \mathrm{C}$ for $6 \mathrm{~h}$ using a shaker. The initial electrical conductivity $\left(\mathrm{E}_{1}\right)$ was read using a FE30 conductivity meter (Mettler Toledo, Shanghai, China). The samples were then boiled at $95^{\circ} \mathrm{C}$ for $60 \mathrm{~min}$ and cooled to $25^{\circ} \mathrm{C}$ before being measured again for electrical conductivity $\left(E_{2}\right)$. The relative electrolyte leakage (REL) was estimated using the following formula: REL (\%) $=E_{1} / E_{2} \times$ 100. The relative injury to cell membranes after heat stress treatment $\left(47^{\circ} \mathrm{C}\right)$ was calculated using the following formula: RII (relative injury index) $=\mathrm{T}_{\mathrm{REL}} / \mathrm{C}_{\mathrm{REL}}$, where $\mathrm{T}$ and $\mathrm{C}$ refer to the heat stress $\left(47^{\circ} \mathrm{C}\right)$ and control $\left(25^{\circ} \mathrm{C}\right)$ temperatures, respectively [14].

The photosynthetic $\mathrm{O}_{2}$ evolution rates of the leaf discs were measured using a ChloroLab-2 liquid-phase oxygen electrode system (Hansatech Instruments, King's Lynn, Norfolk, UK), as described previously [46]. The heattreated leaf discs $(5.5 \mathrm{~cm}$ in diameter) were first adapted at $25^{\circ} \mathrm{C}$ in the dark for $30 \mathrm{~min}$, then cut into smaller leaf discs $(1 \mathrm{~cm}$ in diameter) that were immediately placed into a reaction chamber filled with $1.5 \mathrm{ml} 50 \mathrm{mM}$ Hepes- $\mathrm{KOH}$ ( $\mathrm{pH}$ 7.2), $0.5 \mathrm{mM} \mathrm{CaSO}_{4}$ and $20 \mathrm{mM} \mathrm{NaHCO}_{3}$. At the same time, the leaf discs were exposed to a photon flux density of $800 \mu \mathrm{mol} \mathrm{m} \mathrm{m}^{-2} \mathrm{~s}^{-1}$, which was provided by an array of light-emitting diodes. After $10 \mathrm{~min}$ of equilibration under this light, the $\mathrm{O}_{2}$ evolution was measured, and the data were continuously monitored for $10 \mathrm{~min}$. The $\mathrm{O}_{2}$ evolution rate was calculated over the last $3 \mathrm{~min}$ of measurement [47].

The OJIP test was conducted using a Handy Plant Efficiency Analyzer after the heat-stressed leaf discs had been adapted at $25^{\circ} \mathrm{C}$ for $30 \mathrm{~min}$ in the dark. The OJIP test was performed under a saturating photon flux density of $3000 \mu \mathrm{mol} \mathrm{m} \mathrm{m}^{-2} \mathrm{~s}^{-1}$ provided by an array of three light-emitting diodes (peak $650 \mathrm{~nm}$ ). The fluorescence signals were recorded within a time span from $10 \mu \mathrm{s}$ to $1 \mathrm{~s}$, with a data acquisition rate of $10 \mu \mathrm{s}$ for the first $2 \mathrm{~ms}$ and every $1 \mathrm{~ms}$ thereafter. The following data from the original measurements were used: $F_{k}$ : the fluorescence intensity at $300 \mu \mathrm{s}$ [required for the calculation of the initial slope (M) of the relative variable fluorescence $(\mathrm{V})$ kinetics and $\mathrm{W}_{\mathrm{k}}$ ]; 
$\mathrm{F}_{\mathrm{j}}$ : the fluorescence intensity at $2 \mathrm{~ms}$ (the J-step); $\mathrm{F}_{\mathrm{i}}$ : the fluorescence intensity at $30 \mathrm{~ms}$ (the I-step); and $\mathrm{F}_{\mathrm{m}}$ : the maximal fluorescence intensity (the P-step). The derived parameters were as follows: $F_{o}$, the fluorescence intensity at $50 \mu \mathrm{s} ; \mathrm{W}_{\mathrm{k}}$, calculated as $\mathrm{W}_{\mathrm{k}}=\left(\mathrm{F}_{\mathrm{k}}-\mathrm{F}_{\mathrm{o}}\right) /\left(\mathrm{F}_{\mathrm{j}}-\mathrm{F}_{\mathrm{o}}\right)$ and assumed to represents the damage to the oxygen evolving complex (OEC) of PSII; and $\mathrm{RC}_{\mathrm{QA}}$, calculated as the number of active PSII RCs per cross section (CS) at $t=t_{m}$ using the formula $\mathrm{RC}_{\mathrm{QA}}=\mathrm{RC} / \mathrm{CS}_{\mathrm{m}}=\phi_{\mathrm{Po}_{\mathrm{o}}} \times\left(\mathrm{V}_{\mathrm{j}} / \mathrm{M}_{\mathrm{o}}\right) \times\left(\mathrm{ABS} / \mathrm{CS}_{\mathrm{m}}\right)$ and assumed to represent the density of $\mathrm{Q}_{\mathrm{A}}$-reducing reaction centers (RCs). Here, ABS represents the total photon flux absorbed by the PSII antenna pigments. According to the energy flux theory proposed by Strasser et al. [47], the total ABS is partially trapped by the PSII $R C s$, and the fraction of the ABS used to reduce $Q_{A}$ is labeled as TR, whereas the electron transport flux from $\mathrm{Q}_{\mathrm{A}}$ to $\mathrm{Q}_{\mathrm{B}}$ is labeled as ET. The yield indices or flux ratios can then be derived as follows: the parameter $\phi_{\text {Po }}$, representing the maximum quantum yield of primary photochemistry, is calculated as the ratio of TR/ABS at $\mathrm{t}=0$ using the equation $\phi_{\mathrm{Po}_{\mathrm{o}}}=\mathrm{TR}_{\mathrm{o}} / \mathrm{ABS}=1-\mathrm{F}_{\mathrm{o}} / \mathrm{F}_{\mathrm{m}}=$ $\mathrm{F}_{\mathrm{v}} / \mathrm{F}_{\mathrm{m}}$; the parameter $\phi_{\mathrm{Eo}}$, representing the quantum yield

\begin{tabular}{|c|c|}
\hline $\begin{array}{l}\text { Fluorescence } \\
\text { parameters }\end{array}$ & Fluorescence parameters description \\
\hline \multicolumn{2}{|l|}{ Extracted parameters } \\
\hline $\mathrm{F}_{\mathrm{t}}$ & $\begin{array}{l}\text { Fluorescence intensity at time } t \text { after onset } \\
\text { of actinic illumination }\end{array}$ \\
\hline $\mathrm{F}_{50 \mu \mathrm{s}}$ & $\begin{array}{l}\text { Minimum reliable recorded fluorescence at } \\
50 \mu \text { s with the Handy PEA }\end{array}$ \\
\hline$F_{k}\left(F_{300 \mu s}\right)$ & Fluorescence intensity at $300 \mu \mathrm{s}$ \\
\hline$F_{p}$ & $\begin{array}{l}\text { Maximum recorded (=maximum possible) } \\
\text { fluorescence at P-step }\end{array}$ \\
\hline Area & $\begin{array}{l}\text { Total complementary area between } \\
\text { fluorescence induction curve and } \mathrm{F}=F_{\mathrm{m}}\end{array}$ \\
\hline \multicolumn{2}{|l|}{ Derived parameters } \\
\hline$F_{0} \equiv F_{50 \mu s}$ & $\begin{array}{l}\text { Minimum fluorescence, when all PSII RCs are } \\
\text { open }\end{array}$ \\
\hline$F_{m}=F_{p}$ & $\begin{array}{l}\text { Maximum fluorescence, when all PSII RCs are } \\
\text { closed }\end{array}$ \\
\hline$V_{j}=\left(F_{j}-F_{o}\right) /\left(F_{m}-F_{o}\right)$ & $\begin{array}{l}\text { Relative variable fluorescence at the J-step } \\
(2 \mathrm{~ms})\end{array}$ \\
\hline$V_{i}=\left(F_{i}-F_{0}\right) /\left(F_{m}-F_{0}\right)$ & $\begin{array}{l}\text { Relative variable fluorescence at the l-step } \\
(30 \mathrm{~ms})\end{array}$ \\
\hline$W_{k}=\left(F_{k}-F_{0}\right) /\left(F_{j}-F_{o}\right)$ & $\begin{array}{l}\text { Representing the damage to oxygen } \\
\text { evolving complex (OEC) }\end{array}$ \\
\hline$M_{o}=4\left(F_{k}-F_{o}\right) /\left(F_{m}-F_{o}\right)$ & $\begin{array}{l}\text { Approximated initial increment (in ms-1) of } \\
\text { the relative variable fluorescence }\end{array}$ \\
\hline$F_{v} / F_{m}=1-\left(F_{o} / F_{m}\right)$ & $\begin{array}{l}\text { Maximum quantum yield of primary } \\
\text { photochemistry at } \mathrm{t}=0\end{array}$ \\
\hline$\varphi_{\text {Eo }}=E T_{o} / A B S=\left(F_{m}-F_{j}\right) / F_{m}$ & Quantum yield for electron transport at $\mathrm{t}=0$ \\
\hline $\begin{array}{l}\mathrm{RC}_{\mathrm{QA}_{1}}=\varphi_{P_{\mathrm{o}}} \times\left(\mathrm{ABS} / \mathrm{CS}_{\mathrm{m}}\right) \times \\
\left(\mathrm{V}_{\mathrm{j}} / \mathrm{M}_{\mathrm{o}}\right)\end{array}$ & $\begin{array}{l}\text { Amount of active PSII RCS ( } Q_{A} \text {-reducing PSII } \\
\text { reaction centers) per CS at } t=m\end{array}$ \\
\hline
\end{tabular}

of the electron transport flux from $\mathrm{Q}_{\mathrm{A}}$ to $\mathrm{Q}_{\mathrm{B}}($ at $\mathrm{t}=0$ ), is calculated using the equation $\phi_{\mathrm{Eo}}=\mathrm{ET}_{\mathrm{o}} / \mathrm{ABS}=\left(\mathrm{F}_{\mathrm{m}}-\mathrm{F}_{\mathrm{j}}\right) /$ $\mathrm{F}_{\mathrm{m}}$. All of these parameters are shown in Table 5.

\section{Evaluation of heat tolerance in different grape cultivars and species using OJIP test}

The heat tolerance of the leaves of 47 grape cultivars (or species) were evaluated in May, June and July of 2012 and June and July of 2013 based on the above heat stress procedures. After the leaf discs were exposed to high temperatures $\left(47^{\circ} \mathrm{C}\right)$ for $40 \mathrm{~min}$, the OJIP test was performed using a Handy Plant Efficiency Analyzer to investigate heat injury which indirectly reflects heat tolerance.

\section{Statistical analysis}

The data were processed using SPSS 13.0 for Windows, and each value of the means and standard errors in the figures represents five replications. Differences were considered significant at a probability level of $P<0.05$ according to Duncan's multiple range comparison.

\section{Competing interests}

The authors declare that they have no competing interests.

\section{Authors' contributions}

XHG performed the experiments and wrote the manuscript. LGJ designed the experiment and reviewed the manuscript. WLJ designed the experiments and wrote the manuscript. LGT and YBF helped perform the experiments. DW helped design the experiment. LSH designed the experiment and reviewed the manuscript. All authors have read and approved the final manuscript.

\section{Authors' information}

Hongguo Xu and Guojie Liu: Co-first author.

\section{Acknowledgements}

This work was supported by the National Natural Science Foundation of China (No. 31270718). We thank Prof. Grant Cramer, University of Nevada, USA for critical reviews of the manuscript.

\section{Author details}

'College of Agronomy and Biotechnology, China Agricultural University, Beijing 100193, China. ${ }^{2}$ Key Laboratory of Plant Resources and Beijing Key Laboratory of Grape Science and Enology, Institute of Botany, the Chinese Academy of Sciences, Beijing 100093, People's Republic of China. ${ }^{3}$ University of Chinese Academy of Sciences, Beijing 100049, People's Republic of China. ${ }^{4}$ Key Laboratory of Plant Germplasm Enhancement and Specialty Agriculture, Wuhan Botanical Garden, the Chinese Academy of Sciences, Wuhan 430074, People's Republic of China.

\section{Received: 13 April 2014 Accepted: 29 May 2014}

Published: 5 June 2014

\section{References}

1. Meier N, Rutishauser T, Pfister C, Wanner H, Luterbacher J: Grape harvest dates as a proxy for Swiss April to August temperature reconstructions back to AD 1480. Geophys Res Lett 2007, 34(20):L20705.

2. Webb LB, Whetton PH, Bhend J, Darbyshire R, Briggs PR, Barlow EWR: Earlier wine-grape ripening driven by climatic warming and drying and management practices. Nat Clim Change 2012, 2(4):259-264.

3. White MA, Diffenbaugh NS, Jones GV, Pal JS, Giorgi F: Extreme heat reduces and shifts United States premium wine production in the 21st century. Proc Natl Acad Sci U S A 2006, 103(30):11217-11222.

4. Vaudour $\mathrm{E}$ : The quality of grapes and wine in relation to geography: notions of terroir at various scales. J Wine Res 2002, 13(2):117-141. 
5. Jones GV, White MA, Cooper OR, Storchmann K: Climate change and global wine quality. Clim Change 2005, 73(3):319-343.

6. Salazar-Parra C, Aguirreolea J, Sanchez-Diaz M, Irigoyen JJ, Morales F: Effects of climate change scenarios on Tempranillo grapevine (Vitis vinifera L.) ripening: response to a combination of elevated $\mathrm{CO}_{2}$ and temperature, and moderate drought. Plant Soil 2010, 337(1-2):179-191.

7. Schultz $\mathrm{H}$ : Climate change and viticulture: A European perspective on climatology, carbon dioxide and UV-B effects. Aust J Grape Wine R 2000, 6(1):2-12.

8. Greer DH, Weston C: Heat stress affects flowering, berry growth, sugar accumulation and photosynthesis of Vitis vinifera cv. Semillon grapevines grown in a controlled environment. Funct Plant Biol 2010, 37(3):206-214.

9. Mori K, Goto-Yamamoto N, Kitayama M, Hashizume K: Loss of anthocyanins in red-wine grape under high temperature. J Exp Bot 2007, 58(8):1935-1945

10. Spayd SE, Tarara JM, Mee DL, Ferguson JC: Separation of sunlight and temperature effects on the composition of Vitis vinifera cv. Merlot berries. Am J Enol Viticult 2002, 53(3):171-182.

11. Wahid A, Gelani S, Ashraf M, Foolad MR: Heat tolerance in plants: an overview. Environ Exp Bot 2007, 61(3):199-223.

12. Badger MR, Bjorkman O, Armond PA: An analysis of photosynthetic response and adaptation to temperature in higher plants: temperature acclimation in the desert evergreen Nerium oleander L. Plant Cell Environ 1982, 5(1):85-99.

13. Berry J, Bjorkman O: Photosynthetic response and adaptation to temperature in higher plants. Annu Rev Plant Physiol Plant Mol Biol 1980, 31:491-543.

14. Chauhan YS, Senboku T: Thermostabilities of cell-membrane and photosynthesis in cabbage cultivars differing in heat tolerance. J Plant Physiol 1996, 149(6):729-734.

15. Herzog $\mathrm{H}$, Chai-Arree W: Gas exchange of five warm-season grain legumes and their susceptibility to heat stress. J Agron Crop Sci 2012, 198(6):466-474.

16. Stafne ET, Clark JR, Rom CR: Leaf gas exchange characteristics of red raspberry germplasm in a hot environment. Hortscience 2000 35(2):278-280

17. Stafne ET, Clark JR, Rom CR: Leaf gas exchange response of 'Arapaho' blackberry and six red raspberry cultivars to moderate and high temperatures. Hortscience 2001, 36(5):880-883.

18. Nagarajan S, Bansal KC: Measurement of cellular membrane thermostability to evaluate foliage heat tolerance of potato. Potato Res 1986, 29(1):163-167.

19. Rahman HU, Malik SA, Saleem M: Heat tolerance of upland cotton during the fruiting stage evaluated using cellular membrane thermostability. Field Crop Res 2004, 85(2-3):149-158.

20. Srinivasan A, Takeda H, Senboku T: Heat tolerance in food legumes as evaluated by cell membrane thermostability and chlorophyll fluorescence techniques. Euphytica 1996, 88(1):35-45.

21. Rosyara UR, Subedi S, Duveiller E, Sharma RC: The effect of spot blotch and heat stress on variation of canopy temperature depression, chlorophyll fluorescence and chlorophyll content of hexaploid wheat genotypes. Euphytica 2010, 174(3):377-390.

22. Rosyara UR, Subedi S, Duveiller E, Sharma RC: Photochemical efficiency and SPAD value as indirect selection criteria for combined selection of spot blotch and terminal heat stress in wheat. J Phytopathol 2010, 158 $(11-12): 813-821$

23. Xu WW, Subudhi PK, Crasta OR, Rosenow DT, Mullet JE, Nguyen HT: Molecular mapping of QTLs conferring stay-green in grain sorghum (Sorghum bicolor L. Moench). Genome 2000, 43(3):461-469.

24. Basra AS, Cheema DS, Dhillongrewal R, Singh S, Basra RK: Proline and polyamine accumulation in relation to heat tolerance in tomato. In Adaptation of Food Crops to Temperature and Water Stress. ; 1993:493-495.

25. Allakhverdiev SI, Kreslavski VD, Klimov W, Los DA, Carpentier R, Mohanty P: Heat stress: an overview of molecular responses in photosynthesis. Photosynth Res 2008, 98(1-3):541-550.

26. Stefanov D, Petkova $V$, Denev ID: Screening for heat tolerance in common bean (Phaseolus vulgaris L.) lines and cultivars using JIP-test. Sci HorticAmsterdam 2011, 128(1):1-6.

27. Wise RR, Olson AJ, Schrader SM, Sharkey TD: Electron transport is the functional limitation of photosynthesis in field-grown Pima cotton plants at high temperature. Plant Cell Environ 2004, 27(6):717-724.
28. Govindjee: 63 Years since Kautsky - chlorophyll-a fluorescence. Aust J Plant Physiol 1995, 22(2):131-160.

29. Strasser BJ: Donor side capacity of Photosystem II probed by chlorophyll a fluorescence transients. Photosynth Res 1997, 52(2):147-155.

30. Strasser RJ, Srivastava A, Tsimilli-Michael M: The fluorescence transient as a tool to characterize and screen photosynthetic samples. In Probing photosynthesis: mechanisms, regulation and adaptation. Edited by Yunus M, Pathre U, Mohanty P. London: Taylor and Francis; 2000:445-483.

31. Lin $\mathrm{ZH}$, Chen $L \mathrm{~S}$, Chen $\mathrm{RB}$, Zhang $\mathrm{FZ}$, Jiang $\mathrm{HX}$, Tang $\mathrm{N}$ : $\mathrm{CO}_{2}$ assimilation, ribulose-1,5-bisphosphate carboxylase/oxygenase, carbohydrates and photosynthetic electron transport probed by the JIP-test, of tea leaves in response to phosphorus supply. BMC Plant Biol 2009, 9:43

32. Srivastava A, Guisse B, Greppin H, Strasser RJ: Regulation of antenna structure and electron transport in Photosystem II of Pisum sativum under elevated temperature probed by the fast polyphasic chlorophyll $a$ fluorescence transient: OKJIP. Bba-Bioenerg 1997, 1320(1):95-106.

33. Strasser R, Srivastava A, Tsimilli-Michael M: Screening the vitality and photosynthetic activity of plants by fluorescence transient. In Crop Improvement for Food Security. ; 1999:79-126.

34. Molina-Bravo R, Arellano C, Sosinski BR, Fernandez GE: A protocol to assess heat tolerance in a segregating population of raspberry using chlorophyll fluorescence. Sci Hortic-Amsterdam 2011, 130(3):524-530.

35. Nyarko G, Alderson PG, Craigon J, Murchie E, Sparkes DL: Comparison of cell membrane thermostability and chlorophyll fluorescence parameters for the determination of heat tolerance in ten cabbage lines. $J$ Hortic $\mathrm{SCl}$ Biotech 2008, 83(5):678-682.

36. Sharma DK, Andersen SB, Ottosen CO, Rosenqvist E: Phenotyping of wheat cultivars for heat tolerance using chlorophyll $a$ fluorescence. Funct Plant Biol 2012, 39(10-11):936-947.

37. Weng JH, Lai MF: Estimating heat tolerance among plant species by two chlorophyll fluorescence parameters. Photosynthetica 2005, 43(3):439-444

38. Georgieva K, Fedina I, Maslenkova L, Peeva V: Response of chlorina barley mutants to heat stress under low and high light. Funct Plant Biol 2003, 30(5):515-524

39. He J, Khoo GH, Hew CS: Susceptibility of CAM Dendrobium leaves and flowers to high light and high temperature under natural tropical conditions. Environ Exp Bot 1998, 40(3):255-264.

40. Chen HX, Li PM, Gao HY: Alleviation of photoinhibition by calcium supplement in salt-treated Rumex leaves. Physiol Plantarum 2007, 129(2):386-396

41. Li PM, Cheng LL, Gao HY, Jiang CD, Peng T: Heterogeneous behavior of PSII in soybean (Glycine max) leaves with identical PSII photochemistry efficiency under different high temperature treatments. J Plant Physiol 2009, 166(15):1607-1615.

42. Cao J: Govindjee: chlorophyll $a$ fluorescence transient as an indicator of active and inactive Photosystem- II in thylakoid membranes. Biochim Biophys Acta 1990, 1015(2):180-188.

43. Chen LS, Cheng LL: The sun-exposed peel of apple fruit has a higher photosynthetic capacity than the shaded peel. Funct Plant Biol 2007, 34(11):1038-1048.

44. Chen LS, Li PM, Cheng LL: Comparison of thermotolerance of sun-exposed peel and shaded peel of 'Fuji' apple. Environ Exp Bot 2009, 66(1):110-116.

45. Strasser RJ, Stirbet AD: Heterogeneity of Photosystem II probed by the numerically simulated chlorophyll $a$ fluorescence rise (O-J-I-P). Math Comput Simulat 1998, 48(1):3-9.

46. Sage RF, Kubien DS: The temperature response of C-3 and C-4 photosynthesis. Plant Cell Environ 2007, 30(9):1086-1106.

47. Strasser RJ, Srivastava A: Govindjee: polyphasic chlorophyll-alpha fluorescence transient in plants and cyanobacteria. Photochem Photobio 1995, 61(1):32-42.

doi:10.1186/1471-2229-14-156

Cite this article as: Xu et al.: Comparison of investigation methods of heat injury in grapevine (Vitis) and assessment to heat tolerance in different cultivars and species. BMC Plant Biology 2014 14:156. 